\title{
P02.70. Feasibility and effect of chair massage offered to nurses during working hours on stress related symptoms: a pilot study
}

\author{
D Engen, B Bauer, A Vincent, C Luedtke, L Loehrer, S Cha, T Chon, L Dion, N Rodgers, D Wahner-Roedler* \\ From International Research Congress on Integrative Medicine and Health 2012 \\ Portland, Oregon, USA. 15-18 May 2012
}

\section{Purpose}

To assess the feasibility and effect of chair massage offered to hospital nurses during working hours on stress related symptoms.

\section{Methods}

Single arm study performed between 10/15/2010 and 12/ $24 / 2010$ at an academic medical center. A mass e-mail was sent to all nurses working in an inpatient psychiatric and an outpatient pain rehabilitation unit. The first 40 respondents were enrolled; two were excluded due to missing enrollment data. A 15 minute chair massage once a week for 10 weeks was provided by one of three Certified Massage Therapists available 3 days a week. Instruments used included the Perceived Stress Scale (PSS-14), Smith Anxiety Scale (SAS), and Linear Analogue Scale Assessment (LASA) scale. Mean and standard deviations of PSS-14, SAS and LASA scores at baseline and at 10 weeks were calculated and analyzed with the paired t-test. Any p-value $<0.05$ was considered statistically significant.

\section{Results}

The median age of 38 participants ( 5 males, 33 females) was 47 years (range 21-65). All participants completed the 3 instruments used at the beginning and end of the study. Of 380 available massage appointments, 278 were used (mean 7.13, range 1-10 massages per participant). Stress related symptoms improved as follows: the mean PSS-14 score decreased from 17.85 to $14.92(\mathrm{p}=0.0015)$, and the mean SAS score from 49.45 to 40.95 ( $\mathrm{p}<0.0001)$. The mean LASA score increased from 42.39 to 44.84 $(\mathrm{p}=0.0055)$. Thirty participants $(78.95 \%)$ felt that their

Mayo Clinic, Rochester, USA overall job satisfaction improved because of the massages, and $23(60.53 \%)$ were willing to pay $\$ 10$ to $\$ 25$ for a 15 minute chair massage if available at work.

\section{Conclusion}

Offering chair massages for nurses in a psychiatric/pain rehabilitation unit during working hours - although difficult to do due to busy clinical schedules - reduced stress related symptoms significantly and was highly appreciated by the nurses.

Published: 12 June 2012

doi:10.1186/1472-6882-12-S1-P126

Cite this article as: Engen et al.: P02.70. Feasibility and effect of chair massage offered to nurses during working hours on stress related symptoms: a pilot study. BMC Complementary and Alternative Medicine 2012 12(Suppl 1):P126.

\section{Submit your next manuscript to BioMed Central and take full advantage of: \\ - Convenient online submission \\ - Thorough peer review \\ - No space constraints or color figure charges \\ - Immediate publication on acceptance \\ - Inclusion in PubMed, CAS, Scopus and Google Scholar \\ - Research which is freely available for redistribution

(C) 2012 Engen et al; licensee BioMed Central Ltd. This is an Open Access article distributed under the terms of the Creative Commons Attribution License (http://creativecommons.org/licenses/by/2.0), which permits unrestricted use, distribution, and reproduction in any medium, provided the original work is properly cited. 